\title{
Clinical implementation of a new electronic brachytherapy system for skin brachytherapy
}

\author{
Olga Pons-Llanas, MD', Rosa Ballester-Sánchez, MD², Francisco Javier Celada-Álvarez, MD!' Cristian Candela-Juan, MScl, \\ Teresa Garcia-Martínez, MsD³, Margarita Llavador-Ros, MD ${ }^{4}$, Rafael Botella-Estrada, MD, PhD², Christopher A. Barker, MD5 \\ Antonio Ballesta, MD6, Alejandro Tormo-Micó, MD', Silvia Rodriguez, MD, PhD7, Jose Perez-Calatayud, PhD',7 \\ 'Radiotherapy Department, La Fe University and Polytechnic Hospital, Valencia, Spain, ${ }^{2}$ Dermatology Department, La Fe University and \\ Polytechnic Hospital, Valencia, Spain, ${ }^{3}$ Radiation Physics Department, La Ribera University Hospital, Valencia, Spain, ${ }^{4}$ Pathology Department, \\ La Fe University and Polytechnic Hospital, Valencia, Spain, ${ }^{5}$ Department of Radiation Oncology, Memorial Sloan-Kettering Cancer Center, \\ New York, USA, 'Radiology Department, La Fe University and Polytechnic Hospital, Valencia, Spain, ${ }^{7}$ Radiotherapy Department, Benidorm \\ Hospital, Alicante, Spain
}

\begin{abstract}
Although surgery is usually the first-line treatment for nonmelanoma skin cancers, radiotherapy (RT) may be indicated in selected cases. Radiation therapy as primary therapy can result in excellent control rates, cosmetics, and quality of life. Brachytherapy is a radiation treatment modality that offers the most conformal option to patients. A new modality for skin brachytherapy is electronic brachytherapy. This involves the placement of a high dose rate X-ray source directly in a skin applicator close to the skin surface, and therefore combines the benefits of brachytherapy with those of low energy X-ray radiotherapy. The Esteya electronic brachytherapy system is specifically designed for skin surface brachytherapy procedures. The purpose of this manuscript is to describe the clinical implementation of the new Esteya electronic brachytherapy system, which may provide guidance for users of this system. The information covered includes patient selection, treatment planning (depth evaluation and margin determination), patient marking, and setup. The justification for the hypofractionated regimen is described and compared with others protocols in the literature. Quality assurance (QA) aspects including daily testing are also included. We emphasize that these are guidelines, and clinical judgment and experience must always prevail in the care of patients, as with any medical treatment. We conclude that clinical implementation of the Esteya brachytherapy system is simple for patients and providers, and should allow for precise and safe treatment of nonmelanoma skin cancers.
\end{abstract}

Key words: basal cell carcinoma, electronic brachytherapy, Esteya, fractionation, patient setup, skin cancer.

\section{Purpose}

Basal cell carcinoma (BCC) is a common cancer in humans. It is a skin cancer caused by exposure to ultraviolet radiation and the incidence increases with age [1]. It is a malignant locally invasive epidermal tumor with a good prognosis due to slow growth rate and low metastatic potential. Morbidity results from local invasion and tissue destruction.

Although surgery is usually the first line treatment for non-melanoma skin cancers, radiotherapy (RT) may be indicated in selected cases [2]. Other treatment modalities include electrodessication and curettage, cryotherapy, surgical excision (including Mohs surgery), topical therapy, and photodynamic therapy [3-6]. The choice of appropriate therapy is dependent upon the characteristics of the lesion and patient-specific factors including patient age, general condition, comorbidities, anticoagulant medication, lesion size and location, and histological type. According to the American National Comprehensive Cancer Network (NCCN) guidelines [7], surgery and radiation therapy are the first line treatment options; topical therapies should be reserved for those patients where surgery or radiation therapy is contraindicated or impractical [7].

Radiation therapy as primary treatment modality can result in excellent control rates, cosmesis, and quality of life. Brachytherapy is a form of radiation therapy that offers the most conformal option to patients. In our institutions, the brachytherapy treatment has been performed using a radionuclide based applicators with excellent results for both local control and cosmesis [8].

Electronic brachytherapy is a new modality for skin brachytherapy and it involves placing a high dose rate $\mathrm{X}$-ray source close to the skin surface. This method there- 
fore combines the benefits of brachytherapy with those of low energy $X$-ray radiation therapy. The Esteya ${ }^{\circledR}$ (Elekta $\mathrm{AB}$, Stockholm, Sweden) electronic brachytherapy system is specifically designed for surface brachytherapy procedures, with a $69.5 \mathrm{kV}$ X-ray source. Robust and simple machine quality assurance (QA) and a reliable X-ray source minimize downtime, and therefore improve the user experience and clinic efficiency. This machine has very easy handling and very efficiently adapts to flat lesion location.

Recently, García-Martínez et al. [9] presented the dosimetric characteristics of the Esteya electronic brachytherapy system, as well as the methodology to perform the commissioning of this unit. Flatness, symmetry and penumbra, percentage depth dose curves (PDD), kV stability, half value layer (HVL), surface dose rate, spectrum, linearity, and leakage radiation were evaluated for a set of circular applicators.

Compared to existing brachytherapy techniques based on radioactive nuclides, the Esteya system emits a less energetic and more collimated radiation beam, thus producing less scattered radiation. This results in a very small penumbra $(\leq 1 \mathrm{~mm})$, a lower peripheral dose (i.e. less radiation to tissues outside the beam direction), and the need for only a minimally shielded environment [9]. In addition, electronic brachytherapy offers a higher dose rate such that the fraction treatment time is reduced to only 2-3 minutes. The depth-dose gradient with Esteya ( $7 \%$ per $\mathrm{mm})$ is also smaller than the dose gradient of radionuclide-based applicators (e.g. $10 \%$ per $\mathrm{mm}$ for the Valencia applicators [10]). The latter results in a lower entrance dose for Esteya but a higher dose to deeper healthy tissues.

The purpose of this work is to describe the clinical implementation of the new electronic brachytherapy system Esteya, which may provide guidance for users of this system. The following aspects are considered: patient selection, patient preparation and outcome review, patient marking and setup, fractionation, and quality assurance.

\section{Procedure}

\section{Patient selection}

Patients with basal cell carcinoma who are not candidates for surgery due to patient or tumor characteristics are considered for radiation therapy. Patients should be adults with a primary superficial or nodular basal cell carcinoma confirmed by histopathologic examination. The clinical stage could be T1 or T2 (according to American Joint Committee on Cancer (AJCC) 2010 criteria [11]). The maximum diameter of the lesion should be $20 \mathrm{~mm}$ and the maximum depth of invasion 3-4 mm (measured by punch biopsy and/or ultrasonography). Tumors with high-risk pathologic features (morpheaform, sclerosing, mixed, infiltrative, or micronodular growth pattern or perineural invasion) or that are poorly defined and should not be treated with brachytherapy.

Brachytherapy is relatively contraindicated in recurrent basal cell carcinomas, or those adjacent to or overlapping with a region of a burn or a scar. Basal cell car- cinomas occurring in an area that previously received high doses of radiation therapy are also inappropriate for treatment. Due to applicator design, those basal cell carcinomas located on irregular surfaces (ie. the target area is not flat) are also excluded. Other exclusion criteria for radiation therapy are: compromised lymphatic drainage or vascular supply, an inflammatory process in the target area, pregnancy or lactation, collagen vascular disease (lupus, scleroderma, rheumatoid arthritis), poorly controlled diabetes $\left(\mathrm{HbA}_{1 \mathrm{c}}>7 \%\right)$, genetic disorders predisposing patients to skin cancers or radiation sensitivity (basal cell nevus syndrome, xeroderma pigmentosum, ataxia telangiectasia mutans), medication use that will affect biologic response to radiation (radiosensitizer or radioprotector), and chemotherapy within 6 weeks of radiation therapy.

\section{Treatment planning}

Treatment times are calculated directly by the application included on the Esteya console, once the applicator size, dose and depth are selected. These values should be verified by users during acceptance and commissioning, using appropriate instrumentation and methodology, as discussed by Garcia-Martinez et al. [9].

The protocol used for treatment was developed by the Memorial Sloan Kettering Cancer Center (New York, USA), Clinica Benidorm (Alicante, Spain), and La Fe University and Polytechnic Hospital (Valencia, Spain).

\section{Depth evaluation}

All tumors are examined by means of high-frequency ultrasound (HFUS) and histopathology to determine tumor depth prior to brachytherapy treatment, as part of a standard procedure. High-frequency ultrasound imaging (using a high resolution B-scan with 18-22 MHz hand-held transducer) is performed to measure the macroscopic depth of the tumor (from the epidermal surface to the deepest hypo-echoic point of the tumor). This is then the gross tumor volume (GTV) depth. Subsequently, a punch biopsy of $3 \mathrm{~mm}$ in diameter may be performed, including the whole dermis. The site of choice to perform the biopsy is the deepest site estimated clinically. This should take no longer than 15 minutes. The biopsy is taken to confirm the diagnosis and to measure the microscopic depth of the tumor.

When considering prescription depth, some authors report that there is a moderate correlation between HFUS and histology, suggesting that HFUS could also be useful to assess tumor depth in brachytherapy $[12,13]$. When comparing the two techniques, it is observed that HFUS is non-invasive and allows measurement in real-time, while a biopsy is an invasive technique and requires a longer time to get results. High-frequency ultrasound allows the depth of the entire tumor to be seen but with less accuracy, compared to a biopsy, which only allows part of the lesion to be examined but with more accuracy.

In a previous work [14], the correlation between biopsy and HFUS was studied in a set of 20 patients and demonstrated the uncertainty associated with HFUS. The conclusions from this study were that a safety depth should be adopted similar to the methodology used in 
ophthalmic brachytherapy according to the Collaborative Ocular Melanoma Study (COMS) protocol [15]. Therefore, the prescription depth is $3 \mathrm{~mm}$ for lesions having a depth of $3 \mathrm{~mm}$ or less; for deeper lesions, the specific lesion depth may be used for prescription, with a maximum of $5 \mathrm{~mm}$.

\section{Margin determination}

The margin of tissue irradiated around the gross target volume (GTV), to account for the subclinical extension of disease around the BCC, is typically a 0.4 to $1 \mathrm{~cm}$ radial margin. Margins which are too close may lead to inadequate tumor coverage and local failure. However margins that are too generous may increase the amount of normal tissue treated, and may unnecessarily increase morbidity. Most studies have shown good outcomes using CTV from GTV expansions of $5 \mathrm{~mm}$ to $1 \mathrm{~cm}$ in relatively large patient cohorts [8,16-18]. A recent publication based on a surgical series, suggests the following recommendations for CTV margins: $10 \mathrm{~mm}$ for $\mathrm{BCC}$ less than $2 \mathrm{~cm}, 13 \mathrm{~mm}$ for BCC larger than $2 \mathrm{~cm}, 11 \mathrm{~mm}$ for squamous cell carcinoma (SCC) less than $2 \mathrm{~cm}$, and 14 $\mathrm{mm}$ for SCC larger than $2 \mathrm{~cm}$ [19]. Recently, by contrast, a prospective study has been performed looking at 200 BCCs of the head and neck removed with 2-mm dermoscopically detected excision, and the authors concluded that $2 \mathrm{~mm}$ dermoscopically detected excision margins can achieve histologically confirmed complete excisions in $98.5 \%$ of cases [20]. Dermoscopy is a non-invasive method for skin examination, which allows the examiner to see the lesion with a magnification ten times greater than with the naked eye, allowing far better evaluation of detail [21]. Classic dermoscopic characteristics of BCC have been defined as arborizing telangiectasia, maple leaf-like areas, large blue-grey ovoid nests, ulceration, multiple blue-grey globules, and spoke-wheel areas [22].

At our institutions, as dermoscopy allows better determination of the tumor, GTV is always assessed with a dermatoscope [21]. A $5 \mathrm{~mm}$ margin is added for the $\mathrm{CTV}$, and an additional $1 \mathrm{~mm}$ margin for the PTV to account for uncertainty of the applicator set up.

\section{Patient marking and set-up}

The following procedure is used for patient marking and set-up:

1) the dermatologist contours the GTV lesion on the patient skin with the help of a dermoscope (see Fig. 1A and B),

2) a radial margin of $4-5 \mathrm{~mm}$ is added to establish the CTV,

3) the minimum applicator that covers the whole CTV is selected to treat the lesion; for example, consider a GTV lesion of $13 \mathrm{~mm} \times 10 \mathrm{~mm}$ size; the CTV has an extension of $23 \mathrm{~mm} \times 20 \mathrm{~mm}$; therefore the collimator to be selected is the one with a diameter of $25 \mathrm{~mm}$ (there are 5 different applicators with diameters 10, 15, 20,25 , and $30 \mathrm{~mm}$ ),

4) in order to center the Esteya beam on the lesion, an applicator specific template has been designed, named La Fe templates (see Fig. 1B); this template shows the use- ful beam with a black circle; the template also has some grooves around it which delineate the external size of the collimator that is going to be used; the grooves are marked on the patient skin with a fine-tipped pen; when the template is removed from the patient's skin, the pen drawing shows where the applicator has to be fitted (Fig. 1C),

5) the applicator selected for the patient's lesion is placed on the exit of the X-ray tube,

6) the applicator is then placed in full contact with the patient's skin surface (Fig. 1D). As previously stated, there is a different template for each applicator size. Figure 2 shows the templates named $\mathrm{La} \mathrm{Fe}$ (Elekta AB, Stockholm, Sweden), as well as the different applicators available. Because the applicator is centered on the lesion using the mark made with the help of the template, the CTV to PTV margin is generally the width of the line, i.e. the width of the groove of the template, which is $1-1.5 \mathrm{~mm}$. The reproducibility of the positioning of the applicator is smaller or equal to this line mark width. In order to avoid that the Esteya applicator comes in direct contact with the lesion, a plastic wrap is placed between the applicator exit window and the patient skin.

It is very important that the patient lies comfortably and in a stable position during the treatment time (about 2 to 3 minutes depending on the prescribed dose, applicator size and prescription depth). Foam may be placed on top of the couch and in some cases it may also be useful to use a vacuum bag in order to keep the patient's skin and the applicator in full contact, and the patient's lesion completely fixed.

The Esteya arm has several degrees of freedom in order to place the applicator in full contact with the surface of the patient, for almost any patient position. This is illustrated in Figure 3, which shows the set-up for different patients. The patient position may change slightly from fraction to fraction. However, since the arm is moved manually, the patient position reproducibility is not a really important issue, as long as the applicator exit surface is always placed in full contact with the lesion.

\section{Dose prescription and fractionation}

To determine the dose and fractionation to be administered, we proceeded to review the literature. Studies for both commercial applicators and molds were analyzed. In order to compare the different fractionations we used both the old Ellis conversion model [23] and the linear-quadratic model [24].

Ellis introduced the concept of Nominal Standard Dose (NSD) in clinical practice in an attempt to allow comparison of different fractionations. It was an exercise in modeling and extrapolation, and it was based on data from Strandquist [25], data which related only to the treatment of skin cancers. Furthermore, this model takes the number of weekly fractions into account. On the other hand, this model ignores the importance of the dose fraction for the long-term effects, so that long-term biological effects have been underestimated.

Today, the linear quadratic model is dominant in the field of radiobiology, and it is commonly used to report 

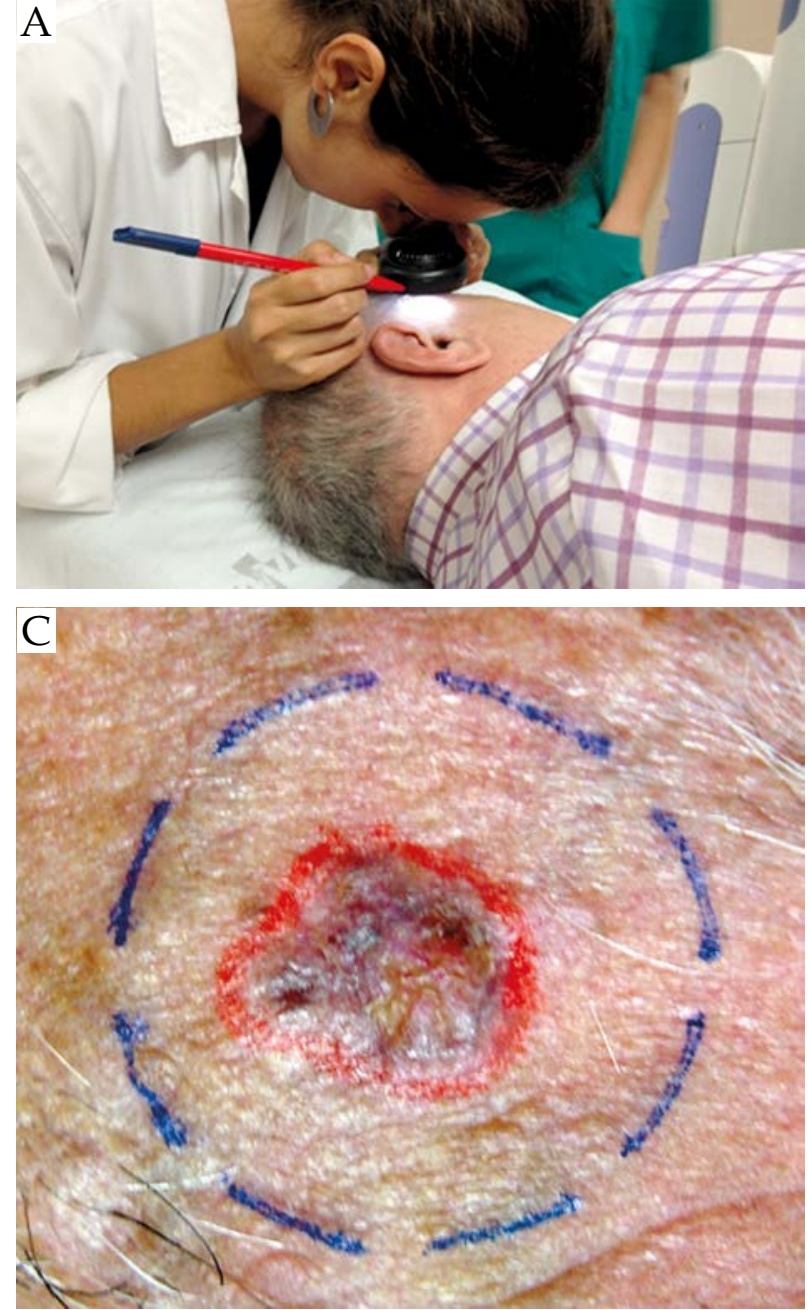

Fig. 1. Procedure of the patient marking and set-up. A) The dermatologist marks the lesion with the help of a dermoscope. B) and C) A template (specific for each applicator size) is placed on the patient's lesion and the external diameter of the applicator is drawn on the patient using the grooves of the template. D) The Esteya arm with the specific applicator is finally placed in contact with the patient's skin surface using its different degrees of freedom

and compare different schemes using both equivalent dose in $2 \mathrm{~Gy}$ fractions $\left(\mathrm{EQD}_{2}\right)$ and biologically equivalent dose (BED) [26,27]. This model is useful in assessing the late effects but it does not take time into account [24].

Therefore, in the literature different fractionations were analyzed using the two models, Ellis and linear quadratic, to determine the biological dose (Table 1). In the case of the linear quadratic model, for the biological equivalence calculation an $\alpha / \beta$ value of 10 is often used for tumor $[26,27]$. However, specific skin cancer publications have suggested an $\alpha / \beta$ value of 8.5 for tumoral tissue [28]. For acute reactions, $\alpha / \beta$ may be 8.8 and 11.2
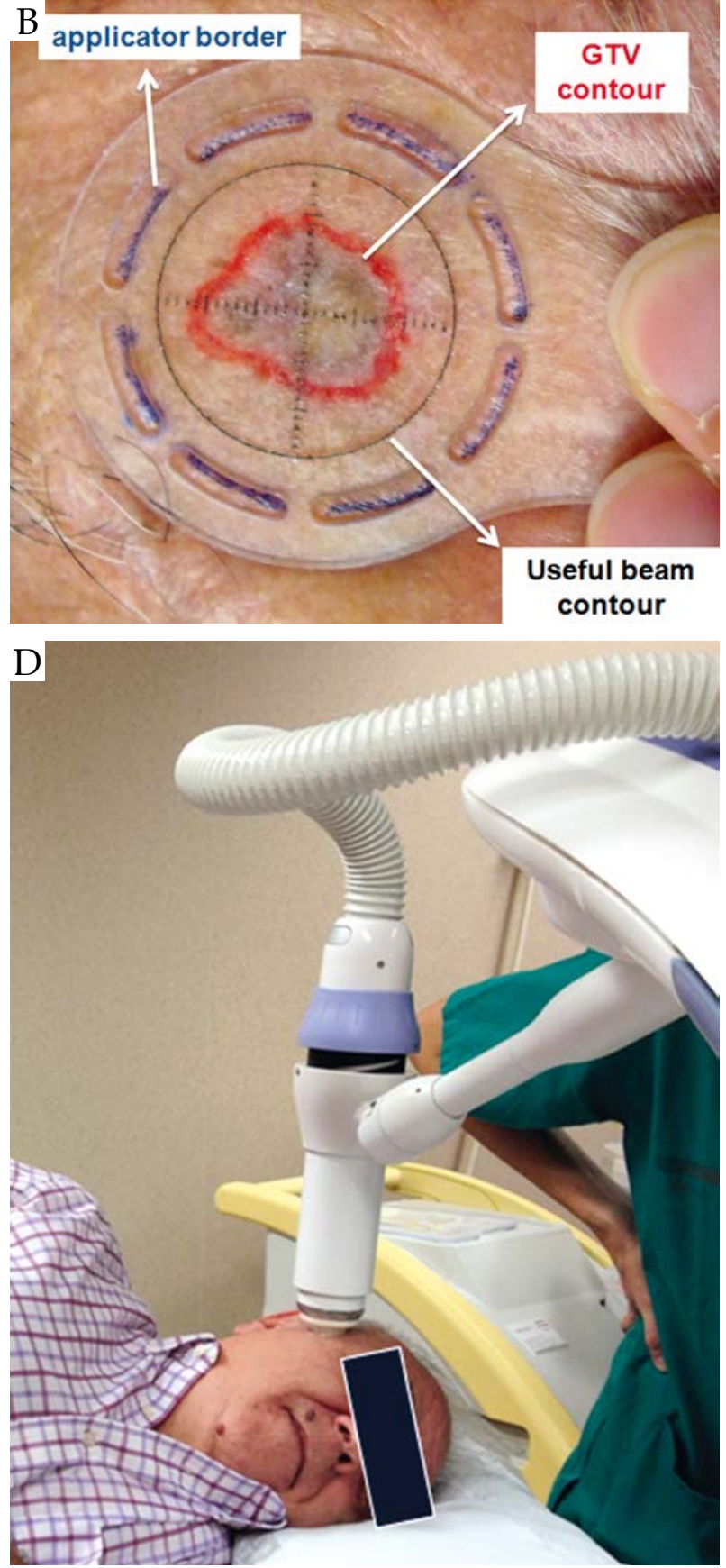

for both erythema and desquamation [29]. With these references, biological equivalent doses were calculated for both $\alpha / \beta$ values of 8 and 10. These data were compared with those from habitual patterns of skin cancer treatments when kilovoltage was used in our hospital (Table 2).

After analyzing, it was decided that our treatment goal was to reach a BED dose of around 70 Gy with $\alpha / \beta 10$ but with a comfortable regimen that would facilitate compliance. Thus, the chosen regimen was 42 Gy in 6 fractions (7 Gy/fraction), two fractions per week, representing a BED of 71.4 Gy with $\alpha / \beta 10$. 


\section{Quality assurance}

According to the current recommendation of the European Society for Therapeutic Radiology and Oncology (ESTRO) [32], each high dose rate unit needs a quality assurance (QA) program that guarantees the proper delivery of the selected radiation dose. For the Esteya unit, on each treatment day it is mandatory to perform a QA before the first patient can be treated. The manufacturing company provides a specially designed QA tool with the system that is connected to the exit of the X-ray tube (see Fig. 4). This tool is composed of 26 diodes placed in two parallel planes [33], which are used to evaluate the output, flatness, and percentage dose depth curve at the same time. After the QA plan has been irradiated (this QA program takes less than 3 minutes), the equipment console automatically shows the comparison with the reference values. Only if results are below an established tolerance, the system allows patients to be treated. Furthermore, following the recommendations, the light indicators, emergency buttons, and interlocks need to be tested by the user every day.

In addition to the above mentioned QA program, in our hospital the unit is checked periodically by means of

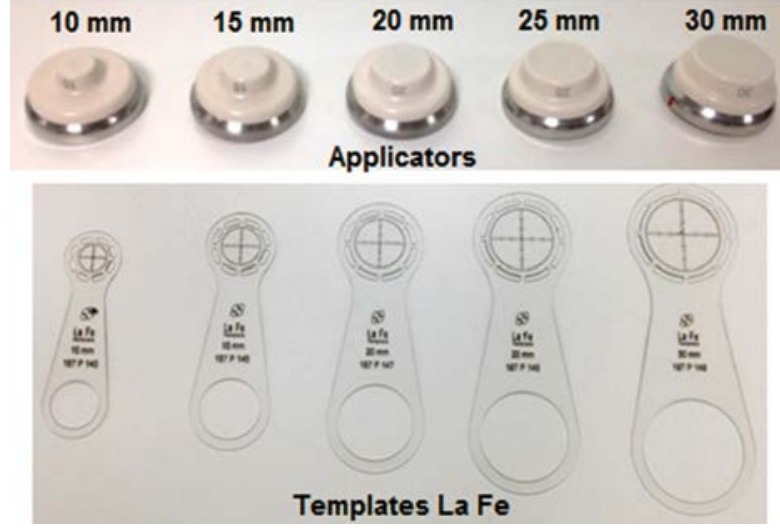

Fig. 2. Esteya applicators of differing collimator diameters and the corresponding templates $\mathrm{La} \mathrm{Fe}$ used to mark the outer diameter of each applicator

an independent method. A parallel plate chamber and solid water slabs are used to measure the absolute surface dose rate of each applicator, as well as the PDD. In addition, film dosimetry is performed to evaluate the uni-
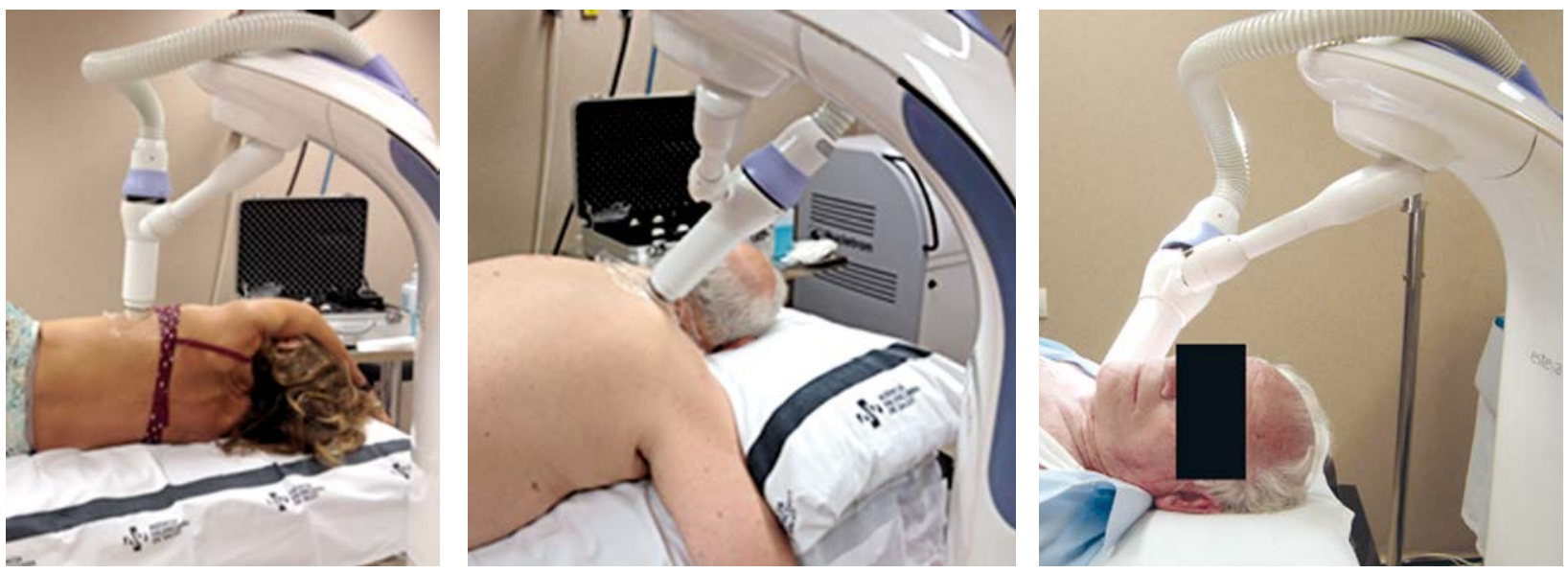

Fig. 3. Images illustrating different set-ups of the patient and the Esteya arm

Table 1. Biological equivalent doses of different skin cancer publications. On the same column, Ellis biological equivalence is presented in the first line, and EQD2 for $\alpha / \beta$ equal 8 and 10 are in the second line

\begin{tabular}{|c|c|c|c|c|c|c|c|}
\hline Author/year & $\begin{array}{l}\text { Treatment } \\
\text { type }\end{array}$ & $\begin{array}{c}\text { Total dose } \\
\text { (Gy) }\end{array}$ & $\begin{array}{l}\text { Fraction } \\
\text { dose (Gy) }\end{array}$ & $\mathrm{N}^{\circ}$ fractions & $\begin{array}{c}\text { Fraction/ } \\
\text { week }\end{array}$ & $\begin{array}{c}\text { Biological } \\
\text { equivalence } \\
\text { Ellis, } \\
\text { EQD2 (8-10) }\end{array}$ & $\begin{array}{l}\text { Biological } \\
\text { equivalence } \\
\text { BED (10 Gy) }\end{array}$ \\
\hline Ghaly, 2008 [22] & Leipzig & 40 & 5 & 8 & 2/week & $\begin{array}{c}56.1 \\
52-50\end{array}$ & 60 \\
\hline Gauden, 2008 [21] & Leipzig & 36 & 3 & 12 & daily & $\begin{array}{c}44.8 \\
39.6-39 \\
\end{array}$ & 46.8 \\
\hline \multirow[t]{2}{*}{ Tormo, 2014 [8] } & Valencia & 42 & 6 & 7 & 2/week & $\begin{array}{c}64.9 \\
58.8-56\end{array}$ & 67.2 \\
\hline & & & 7 & 6 & 2/week & $\begin{array}{c}70.6 \\
63-59.5 \\
\end{array}$ & 71.4 \\
\hline Amendola, 2006 [30] & $\begin{array}{c}\text { Customized } \\
\text { molds }\end{array}$ & 50 & 5 & 10 & 2/week & $\begin{array}{c}70.1 \\
65-62.5 \\
\end{array}$ & 75 \\
\hline Fabrini, 2010 [31] & $\begin{array}{l}\text { Customized } \\
\text { molds }\end{array}$ & 50 & 5 & 10 & 3/week & $\begin{array}{c}75.1 \\
65-62.5\end{array}$ & 75 \\
\hline
\end{tabular}


Table 2. Historical fractionations using the $70 \mathrm{kV}$ setting of a RT-100 Philips Unit and biological equivalences. On the same column, Ellis biological equivalence is presented in the first line, and EQD2 for $\alpha / \beta$ equal 8 and 10 are in the second line

\begin{tabular}{|c|c|c|c|c|c|c|}
\hline \multirow{4}{*}{$\begin{array}{l}\text { Old kV } 70 \text { H La Fe } \\
\text { RT-100 Philips } \\
3 \text { mm depth }\end{array}$} & $\begin{array}{l}\text { Total dose } \\
\text { (Gy) }\end{array}$ & $\begin{array}{l}\text { Fraction dose } \\
\text { (Gy) }\end{array}$ & $\mathrm{N}^{\circ}$ fractions & $\begin{array}{l}\text { Fraction/ } \\
\text { week }\end{array}$ & $\begin{array}{c}\text { Biological } \\
\text { equivalence Ellis, } \\
\text { EQD2 (8-10) }\end{array}$ & $\begin{array}{l}\text { Biological } \\
\text { equivalence } \\
\text { BED (10 Gy) }\end{array}$ \\
\hline & 54 & 3 & 18 & 3/week & $\begin{array}{c}61.61 \\
59.4-58.5\end{array}$ & 70.2 \\
\hline & 45 & 3 & 15 & 3/week & $\begin{array}{c}51.34 \\
49.5-48.8 \\
\end{array}$ & 67.5 \\
\hline & 45 & 5 & 9 & 2/week & $\begin{array}{c}63.1 \\
58.5-56.2\end{array}$ & 67.5 \\
\hline
\end{tabular}

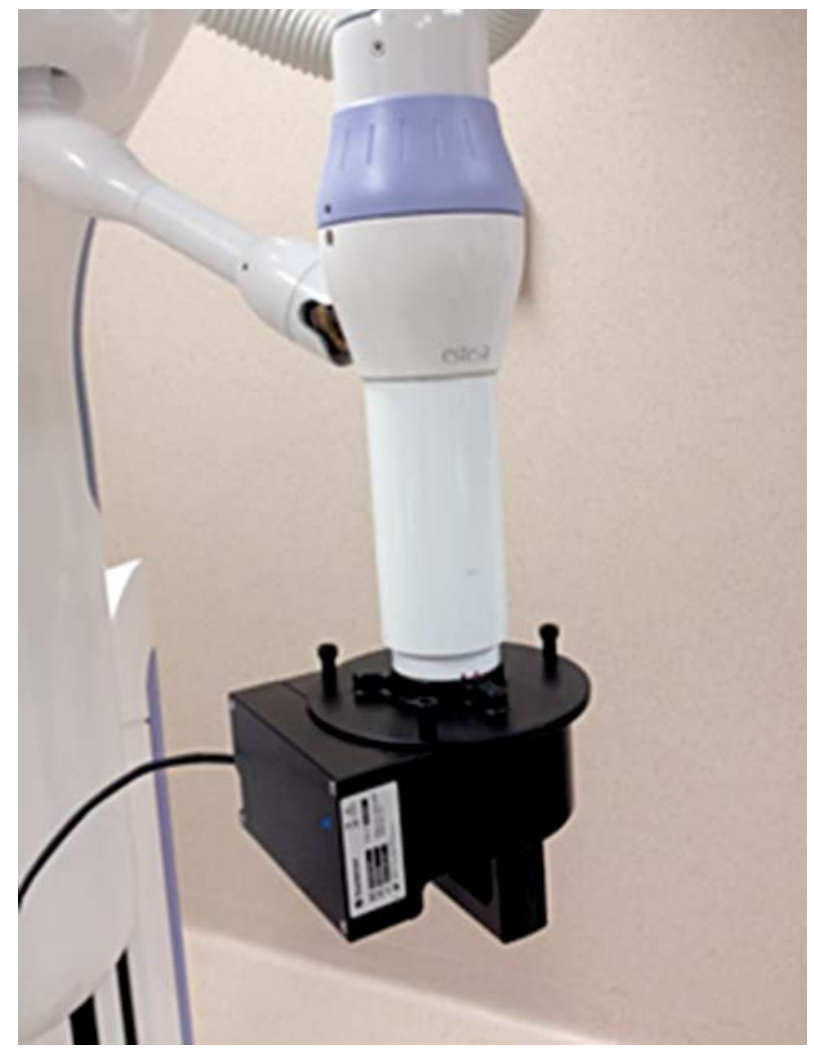

Fig. 4. Esteya unit with the QA tool provided by Elekta, which is composed of 26 diodes placed in two parallel planes in order to check constancy of output, flatness and PDD

formity and, therefore, the integrity of the different applicators. Details on this independent QA program can be found in the work by García-Martínez et al. [9].

For each plan, the treatment time should be verified by an independent calculation. This can be done with a simple spreadsheet with the dataset obtained during commissioning.

\section{Conclusions}

The clinical implementation guidelines for the new electronic brachytherapy system Esteya have been described, including patient selection, treatment planning (depth evaluation and margin determination), patient marking, and patient set-up. The justification of the hypofractionated regimen has been described and compared with others schema in the literature. Quality assurance aspects including daily testing were also included. We emphasize that these are guidelines, and clinical judgment and experience must always prevail in the care of patients, as with any medical treatment.

In conclusion, clinical implementation of the Esteya brachytherapy system is simple for patients and providers, and should allow for precise and safe treatment of nonmelanoma skin cancers.

\section{Acknowledgments}

This study was partially supported by Elekta. The authors want to thanks to Dr Gil'ad Cohen for his review and comments.

\section{Founding sources and disclosure}

This study was supported by (Nucletron - an Elekta Company, Veenendaal, The Netherlands). Funding Sources: This study was supported in part by Generalitat Valenciana (Project PROMETEOII/2013/010) and by Spanish Government under Project No. FIS2013-42156.

Christopher A. Barker has received research funding from, and served as a paid consultant to Nucletron, the manufacturer of Esteya.

\section{References}

1. Lear W, Dahlke E, Murray CA. Basal cell carcinoma: review of epidemiology, pathogenesis, and associated risk factors. J Cutan Med Surg 2007; 11: 19-30.

2. Clark CM, Furniss M, Mackay-Wiggan JM. Basal cell carcinoma: an evidence-based treatment update. Am J Clin Derm 2014; 15: 197-216.

3. Bahner JD, Bordeaux JS. Non-melanoma skin cancers: photodynamic therapy, cryotherapy, 5-fluorouracil, imiquimod, diclofenac, or what? Facts and controversies. Clin Dermatol 2013; 31: 792-798.

4. Fimhaber JM. Diagnosis and treatment of basal cell and squamous cell carcinoma. Am Fam Physician 2012; 86: 161-168.

5. Ormerod A, Rajpara S, Craig F. Basal cell carcinoma. Clin Evid (Online) 2010; 6: 1719

6. Roozeboom MH, Arits AH, Nelemans PJ et al. Overall treatment success after treatment of primary superficial basal cell carcinoma: a systematic review and meta-analysis of randomized and nonrandomized trials. Br J Dermatol 2012; 167: 733-756. 
7. National Comprehensive Cancer Network guidelines 2013 of Basal Cell Skin Cancer.

8. Tormo A, Celada F, Rodriguez S et al. Non-melanoma skin cancer treated with HDR Valencia applicator: clinical outcomes. J Contemp Brachytherapy 2014; 6: 167-172.

9. García-Martínez T, Chan J-P, Perez-Calatayud J et al. Dosimetric characteristics of a new unit for electronic skin brachytherapy. J Contemp Brachytherapy 2014; 6: 1-9.

10. Granero D, Perez-Calatayud J, Jimeno J et al. Design and evaluation of a HDR skin applicator with flattening filter. Med Phys 2008; 35: 495-503.

11. AJCC (American Joint Committee on Cancer). Cancer staging of cutaneus nonmelanoma skin cancer. 2010.

12. Hernández C, del Boz J, de Troya M. Can high-frequency skin ultrasoud be used for the diasgnosis and management of basal cell carcinoma? Actas Dermo-sifiliográficas 2014; 105: 107-111.

13. Nassiri-Kashani M, Sadr B, Fanian F et al. Pre-operative assessment of basal cell carcinoma dimensions using high frequency ultrasonography and its correlation with histopathology. Skin Res Techn 2013; 19: e132-e138.

14. Ballester R, Pons O, Llavador M et al. Depth determination of superficial brachytherapy: Ultrasound vs Histophatology. J Contemp Brachytherapy 2014 [In press].

15. Nag S, Quivey JM, Earle JD et al. The American Brachytherapy Society recommendations for brachytherapy of uveal melanomas. Int J Radiat Oncol Biol Phys 2003; 56: 544-555.

16. Bhatnagar A. Nonmelanoma skin cancer treated with electronic brachytherapy: results at 1 year. Brachytherapy 2013; 12: 134-140.

17. Gauden S, Egan C, Pracy M. HDR brachytherapy for the treatment of the skin cancer using standard surface applicators. Brachytherapy 2008; 7: 159 (Abstract).

18. Ghaly M, Zinkin H, Dannenberg M et al. HDR brachytherapy with standardized surface applicators in the treatment of superficial malignant skin lesions. Int J Radiat Oncol Biol Phys 2008; 72: 505-506.

19. Khan L, Choo R, Bree D et al. Recommendations for CTV margins in radiotherapy planning for non melanoma skin cancer. Radiother Oncol 2012; 104: 263-266.

20. Caresana G, Giardini R. Dermoscopy-guided surgery in basal cell carcinoma. J Eur Acad Dermatol Venereol 2010; 24: 1395 1399.

21. Ballester R, Pons O, Perez-Calatayud J et al. Dermoscopy margin delineation in radiotherapy planning for superficial and nodular basal cell carcinoma. Br J Dermatol 2014 [In press].

22. Giacomel J, Zalaudek I. Dermoscopy of Superficial Basal Cell Carcinoma. Derm Surg 2005; 3: 1710-1713.

23. Ellis F. Dose, time, and fractionation: a clinical hypothesis. Clin Radiol 1969; 20: 1-7.

24. Dale RG. The application of the linear-quadratic dose-effect equation to fractionated and protracted radiotherapy. $\mathrm{Br}$ I Radiol 1985; 58: 515-528.

25. Strandquist M. A study of the cumulative effects of fractionated X-ray treatment based on the experience gained at radiumhemmet with the treatment of cases of carcinoma of the skin and lip. Acta Radiol 1944; 55 (Suppl): 300-304.

26. Potter R, Haie Meder C, van Limbergen E et al. Recommendations from gynaecological (GYN) GEC ESTRO working group (II): concepts and terms in 3D image-based treatment planning in cervix cancer brachytherapy - 3D dose volume parameters and aspects of 3D image-based anatomy, radiation physics, and radiobiology. Radiother Oncol 2006; 78: 67-77.

27. Onishi H, Araki T, Shirato H et al. Stereotactic hypofractionated high-dose irradiation for stage I non-small cell lung carcinoma: clinical outcomes in 245 subjects in a Japanese multiinstitutional study. Cancer 2004; 101: 1623-1631.
28. Trott KR, Maciejewski B, Preuss-Bayer G et al. Dose-response curve and split-dose recovery in human skin cancer. Radiother Oncol 1984; 2: 123-129.

29. Turesson I, Thames HD. Repair capacity and kinetics of human skin during fractionated radiotherapy: erythema, desquamation, and telangiectasia after 3 and 5 year's follow-up. Radiother Oncol 1989; 15: 169-188

30. Amendola B et al. Dermatological applications of HDR using surface applicators using a shorter treat- ment schedule. Brachytherapy 2006; 5: 105 (Abstract).

31. Fabrini MG, Perrone F, De Liguoro M et al. High dose rate brachytherapy in a large squamous cell carcinoma of the hand. Brachytherapy 2008; 7: 270-275.

32. European Society for Therapeutic Radiology and Oncology. ESTRO booklet No. 8: A practical guide to quality control of brachytherapy equipment. Venselaar J, Perez-Calatayud J (eds.). Brussels, 2004.

33. Esteya Electronic Brachytherapy System U87001-User Manual. Doc. No. 777.00193MAN-02DRAFT-374A, 2014. 